ISSN 1518-3483

Licenciado sob uma Licença Creative Commons

\title{
Summaê: um espaço criativo para aprendizagem
}

\author{
Summaê: a creative environment for learning
}

Summaê: un espacio innovador para aprendizaje

\section{Ricardo Ramos Fragelli, Thaís Branquinho Oliveira Fragelli*}

Universidade de Brasília (UnB), Brasília, DF, Brasil

\section{Resumo}

Este artigo apresenta alguns avanços sobre uma metodologia ativa conhecida como Summaê, utilizada em várias regiões do país e em diversos campos do conhecimento. A primeira publicação sobre esse tema data de 2012 e, apesar de os fundamentos serem os mesmos das primeiras experiências feitas em turmas de Engenharia, algumas adaptações foram realizadas para que pudesse ser aplicado de modo mais abrangente, inclusive na educação a distância e na educação corporativa. Além de apresentar a metodologia de forma mais consistente e detalhada, são analisados resultados qualitativos de 18 professores que participaram diretamente da organização de Summaês em suas instituições, com o intuito de estudar as possíveis dificuldades encontradas, principais vantagens, reações dos estudantes e seu engajamento sob a óptica do professor. Os resultados mostram que os docentes tiveram pouca ou nenhuma dificuldade na realização do Summaê e as principais

\footnotetext{
RRF: Doutor em Ciências Mecânicas, e-mail: fragelli@unb.br TBOF: Doutora em Ciências da Saúde, e-mail: tbranquinho@unb.br
} 
reações dos estudantes foram de motivação, alegria, aproximação, divertimento, entusiasmo, concentração e espírito de equipe.

Palavras-chave: Aprendizagem ativa. Aprendizagem criativa. Summaê.

\begin{abstract}
This article presents some advances in an active methodology named Summaê, used in several places in Brazil and in several fields of knowledge. The first paper about this theme was published in 2012 and, despite the basic procedures remains the same, some adaptations were realized for this methodology could be applied in other contexts, include Distance Education and in Corporative Education. In addition to presenting the methodology in a more consistent and detailed manner, qualitative results are analyzed of 18 professors who participated directly in the organization of Summaês in their Institutions in order to study the obstacles, main advantages, reactions of the students and their engagement from the point of view of the professor. The results showed that the professors had little or no difficulty in performing Summaê and the main reactions of the students were motivation, happiness, approach, enjoyment, enthusiasm, concentration and team spirit.
\end{abstract}

Keywords: Active learning. Creative learning. Summaê.

\title{
Resumen
}

Este artículo presenta algunos avances sobre una metodología activa conocida como Summaê, utilizada en varias regiones del Brasil y en diversos campos del conocimiento. La primera publicación sobre este tema fue realizada en 2012 y, a pesar de que los fundamentos son los mismos de las primeras experiencias hechas en las clases de Ingeniería, algunas adaptaciones se realizaron desde entonces para que pudiera ser aplicado de manera más amplia, incluso en la Educación a Distancia y en la Educación Educación Corporativa. Además de presentar la metodología de manera más consistente y detallada, se analizan resultados cualitativos de 18 profesores que participaron directamente en la organización 
de Summaês en sus Instituciones con el propósito de estudiar las posibles dificultades encontradas, principales ventajas, reacciones de los estudiantes y el compromiso de los mismos Bajo la óptica del profesor. Los resultados mostraron que los docentes tuvieron poca o ninguna dificultad en la realización del Summaê y las principales reacciones de los estudiantes fueron de motivación, alegría, acercamiento, diversión, entusiasmo, concentración y espíritu de equipo.

Palabras clave: Aprendizaje activo. Aprendizaje creativo. Summaê.

\section{Introdução}

Diversos programas refletem sobre o problema das habilidades dos estudantes no século XXI. Um exemplo é o Partnership for $21^{\text {st }}$ Century Learning (P21), uma organização não governamental americana que desenvolveu, por meio de alianças com organizações-chave e representantes dos principais assuntos acadêmicos, mapas de habilidades essenciais aos estudantes com base nos desafios que serão enfrentados. Entre as habilidades elencadas, destaca-se a recomendação de que sejam estimulados o pensamento criativo, a capacidade de inovação, a originalidade, a inventividade no trabalho e a capacidade de trabalhar em colaboração na resolução de problemas (P21, 2014). Tais habilidades, desenvolvidas em ambiente educacional, facilitam ao egresso a capacidade de criar novas e eficazes soluções para problemas, estimuladas pelo desejo de mudança (CROPLEY, 2015).

Observa-se, no entanto, que na maioria das vezes os elementos que facilitam o desenvolvimento de tais habilidades estão cada vez mais ausentes em sala de aula (GRAY, 2013). Os currículos das graduações estão se concentrando excessivamente em habilidades técnicas específicas e de grande profundidade, o que é, sim, necessário, mas deixa pouco ou nenhum espaço para desenvolver a capacidade de pensar e agir de maneira criativa e inovadora (CROPLEY, 2015). A forma de conseguir os elementos para melhor favorecer esse processo construtivo e formativo recomendado em sala 
de aula tem sido analisada por pesquisadores que defendem a utilização de estratégias que promovam o espírito lúdico (GRAY, 2013).

Na prática, há críticas de parte dos docentes quanto ao uso de métodos pouco convencionais, mas não há dúvidas de que existem benefícios relacionados ao engajamento e à aquisição de melhores resultados quando o professor propõe-se a conduzir um processo de aprendizagem ativa, no qual permite ao discente o autogerenciamento de sua aprendizagem (HOFFMAN et al., 2014).

O engajamento, que expressa a qualidade emocional e a intensidade comportamental relacionadas ao envolvimento ativo de um aluno durante o processo de aprendizagem, é considerado vital para as atividades acadêmicas (JANG; REEVE; DECI, 2010). Estudos têm demonstrado que os alunos engajados são mais atentos, participativos, interessados e motivados para o aprendizado. Em contrapartida, os que são menos engajados têm notas mais baixas, maior probabilidade de evadir do curso, referem-se mais entediados e ansiosos e estão menos propensos a alcançar as metas educacionais mais elevadas. As pesquisas têm relatado que uma aprendizagem eficaz, considerando qualquer conteúdo, depende do quão os alunos estão engajados nas atividades propostas em sala de aula (REYES et al., 2012).

Nesse contexto, a questão que se faz é: como os professores podem facilitar o engajamento dos seus alunos? Normalmente, a ideia do estudante "desinteressado" está vinculada ao imaginário popular de que é atributo ou traço individual desse indivíduo e não um resultado da estruturação das atividades em sala de aula (REYES et al., 2012). Assim, o ambiente de interação construído pelo docente em sala de aula desempenha um papel importante na motivação e no engajamento dos alunos (PATRICK; KAPLAN; RYAN, 2011). Nesse aspecto, as interações que ocorrem na esfera professor-aluno, como processo social, são capazes de promover resultados no engajamento deste (REYES et al., 2012), o mesmo valendo para as interações entre os próprios estudantes (FRAGELLI; FRAGELLI, 2017).

Um ambiente emocionalmente propício para o aprendizado, formado com base em boas interações professor-aluno (REYES et al., 2012) e aluno-aluno (FRAGELLI; FRAGELLI, 2017), e ambientes de estudo que se 
estendem além da tradicional sala de aula proporcionam novas oportunidades de aprendizagem, ou seja, fenômenos interacionais nos quais estão inclusas declarações, perguntas, modelagem, gestos e sentimentos (TUYAY; JENNINGS; DIXON, 1995). Em outras palavras, as oportunidades de aprendizagem não estão restritas apenas à apresentação unidirecional de conteúdos (TUYAY; JENNINGS; DIXON, 1995).

Desse modo, o docente deve ter em mente que as melhores oportunidades de aprendizagem acontecem quando existem elementos necessários para articular pensamentos e significar atividades, experiências e informações, havendo também interação com novas informações, conectadas ao conhecimento prévio existente (STEWART; JORDAN, 2016), bem como que o ambiente de aprendizagem deve ser emocionalmente propício (REYES et al., 2012).

A literatura aponta que, em um ambiente informal, os elementos citados anteriormente ocorrem com mais naturalidade. Esses ambientes podem ser caracterizados como espaços nos quais os discentes envolvem-se de maneira engajada, com atividades não necessariamente planejadas para o currículo escolar, e que fogem do ambiente tradicional da sala de aula, a exemplo dos museus, acampamentos, centros de ciência, atividades comunitárias, atividades familiares, entre outros (HOFSTEIN; ROSENFELD, 1996; STEWART; JORDAN, 2016). Neles, os objetivos curriculares tendem a ser menos estruturados e padronizados, havendo um espaço para promoção da aprendizagem acidental, envolvendo incógnitas complexas e ambíguas, nas quais os atores estão mais preocupados com o engajamento, resultados afetivos, relações sociointeracionais e desenvolvimento de interesses pessoais do que com assegurar e monitorar o aprendizado (ROCKMAN; BASS; BORSE, 2007; SEFTON-GREEN, 2013; STEWART; JORDAN, 2016).

Mesmo em ambientes escolares formais, é possível transformar os espaços de modo a oferecer oportunidades de aprendizagem que ocorram similarmente em ambientes informais e, na combinação de experiências formais e informais, proporcionar uma melhora nos resultados da aprendizagem (HOFSTEIN; ROSENFELD, 1996). Em outras palavras, ambientes que foram inicialmente planejados para oferecer uma aprendizagem formal 
podem também conter elementos das oportunidades informais, que é o caso do Summaê, metodologia ativa apresentada neste artigo.

A transformação do ambiente age não apenas na aquisição de maior engajamento do discente, mas também na facilitação de um ambiente emocionalmente propício. Contudo, ela não pode ser aleatória. Deve-se ter um planejamento adequado do nível de liberdade dentro do processo de aprendizagem, para que não cause desorientação no discente, a ponto de se sentir ansioso, mesmo no caso de aprendizes adultos (ROGERS, 1973, 1991).

Esse aspecto foi observado em um estudo de Stewart e Jordan (2016), no qual demonstraram que existem fatores ambientais que interferem diretamente nos níveis percebidos de ansiedade. Entre esses fatores, destacaram-se os objetivos (se relacionados à competição ou não), o gerenciamento dos espaços interativos, as relações de poder e a colaboração. Outro resultado apontado no estudo foi a importância da necessidade de instrução direta em alguns momentos, para reduzir o nível de ansiedade provocado pelo ambiente (STEWART; JORDAN, 2016).

Estudos conduzidos por Rogers $(1973,1991)$ observaram esse mesmo aspecto após oferecer liberdade total de escolha aos estudantes sobre o que e como seria aprendido em sala de aula. Essa atitude teve como resultado a percepção aumentada da aflição, adicionada à desmotivação para a aprendizagem. Assim, mesmo sabendo da importância do autogerenciamento para o discente adulto, ele deve ocorrer com o devido planejamento, de forma a proporcionar um nível de liberdade que poderia dar autenticidade aos estudantes (ROGERS, 1973, 1991).

Outro aspecto importante na construção de um ambiente de aprendizagem emocionalmente propício foi apontado no estudo de Lai et al. (2016), que analisou a estratégia de realizar perguntas em classe, utilizada habitualmente, para verificar o nível de entendimento sobre os conceitos trabalhados e, consequentemente, ter uma abordagem pedagógica adaptativa, de acordo com as respostas obtidas. Por meio da análise de expressões faciais e eletroencefalograma, os autores apresentaram figuras divertidas para os estudantes após a realização das perguntas e, como resultado, estes 
se mostraram mais motivados a responder às questões, com aumento nos níveis de atenção e relaxamento (LAI et al., 2016).

Com base nas evidências apresentadas, pode-se afirmar que um caminho interessante para a aprendizagem seria uma estratégia planejada para reduzir níveis percebidos de ansiedade, construindo um ambiente que seja emocionalmente propício para favorecer o engajamento e uma melhor interação professor-aluno e aluno-aluno. A utilização de questões pode ser também uma boa alternativa, desde que os estudantes sintam-se motivados a participar; ainda, o emprego de elementos de jogos e um ambiente lúdico podem ser boas soluções.

Assim, surge como estratégia o Summaê, escopo deste artigo, que constitui uma metodologia ativa e transforma o espaço de aprendizagem em um ambiente lúdico e criativo, com oportunidades inovadoras de aprendizado estimuladas por questões formuladas pelos próprios estudantes e apresentadas por meio de vídeos criativos de maneira gamificada.

\section{Summaê}

O Summaê foi idealizado, em 2011, pelo professor Ricardo Fragelli, com o objetivo de transformar o ambiente de classe nas aulas de Cálculo para os cursos de Engenharia na UnB em um espaço mais interessante, lúdico, gamificado, criativo, colaborativo e com maior engajamento dos estudantes (SUMMAÊ, 2017).

A primeira publicação da metodologia data de 2012 (FRAGELLI et al., 2012) e foca a educação nas áreas de Engenharia e Exatas, havendo poucos detalhes sobre sua realização em outros contextos. Desde então, foram realizados 12 eventos na UnB trabalhando o mesmo conteúdo original, como também organizados outros por professores de outras instituições e cursos, como Administração, Direito, Fisioterapia, Design e Enfermagem. O Summaê também foi aplicado na Educação a Distância (EaD) e na Educação Corporativa, e tais experiências proporcionaram um entendimento mais 
amplo sobre a metodologia, seus pontos principais e inovações, o que será sintetizado neste artigo.

O nome "Summaê" é a junção da palavra "summae" (do latim, somas) com o acento circunflexo "^” e representa a união de pessoas para o estudo de um determinado tema, mas todas vestindo chapéu. O objetivo em utilizar chapéus é caracterizar o evento e tornar o ambiente mais lúdico, quebrando o clima da tradicional sala de aula e oferecendo mais elementos de interação entre os participantes.

Basicamente, os pontos principais que o caracterizam são: existência de uma mesa de professores ou especialistas; alunos veteranos ou pessoal de apoio; perguntas feitas por meio de vídeos criativos; todos os participantes usando chapéus; jogo de perguntas e respostas; escolha dos top chapéus (celebridades do evento); escolha dos melhores vídeos; e desafio final a ser resolvi.do em pequenas equipes lideradas pelo participante com maior pontuação. Alguns elementos adicionais, que fornecem ao Summaê alguma teatralidade e mais dinamismo, são apresentações artísticas e desafios intermediários envolvendo os participantes. Ainda, é possível aumentar o nível artístico da atividade com maquiagens teatrais, fantasias, som, iluminação e decoração temática.

Essa metodologia ativa pode ser utilizada em qualquer nível escolar e com qualquer quantidade de participantes, e já tendo sido aplicada em turmas com 10 estudantes e também com 800, podendo ocupar um período de uma a quatro horas. Em todos esses casos, o mais comum é ser uma atividade peculiar que ocorre em um momento específico ao longo do curso, que aqui será chamado evento.

Sob a óptica do organizador do evento, as etapas que precedem à realização de um Summaê são:

a) Escolha do tema (assunto a ser trabalhado): identificação dos conceitos a ser trabalhados durante o evento, sobre os quais serão produzidos os vídeos com perguntas. No caso de realização de disciplinas escolares, sugere-se utilizar o Summaê no fim do curso, com a última matéria estudada (por exemplo, Revolução Francesa, verbos irregulares ou resolução de sistemas lineares). 
Também é possível trabalhar temas mais gerais ou peculiares à instituição, uma boa escolha para alguns eventos de educação corporativa.

b) Produção de vídeos com perguntas: geralmente, utiliza-se um período superior a 15 dias, para que os participantes, organizados em duplas ou trios, elaborem suas perguntas sobre a temática escolhida. Cada pergunta deve ser apresentada por meio de um vídeo criativo e cada dupla ou trio deve ficar responsável por uma quantidade específica de vídeos (em geral, de dois a cinco vídeos, de acordo com a temática e público-alvo). Os vídeos normalmente são elaborados com base na releitura de filmes famosos, encenações, paródias, músicas autorais, celebridades, personalidades da instituição de ensino, montagens especiais, entre outros, e devem ser enviados ao organizador considerando um prazo com tempo hábil para selecionar aqueles que serão utilizados durante o evento. O site do Summaê (summaeh.com) possui ferramentas para envio e organização dos vídeos para cada evento.

c) Vídeos com respostas: opcionalmente, é possível solicitar que cada dupla ou trio elabore vídeos respondendo às questões feitas por outros estudantes. No site do Summaê, é possível fazer essa correlação entre um vídeo-pergunta e um vídeo-resposta, criando um bom ambiente para estudo.

d) Mesa de professores: um dos pontos mais elogiados pelos estudantes é haver uma mesa formada por professores, com diferentes estilos de ensino. Isso faz com que os alunos aprendam melhor e fiquem mais estimulados, mas também leva os docentes a aprenderem e se inspirar com os estilos e as estratégias pedagógicas dos seus colegas. O principal papel da mesa de professores é a correção e o possível debate das questões formuladas pelos estudantes por meio dos vídeos. 
e) Pessoal de apoio (entidades): para auxiliar nas atividades, é aconselhável convidar algumas pessoas, geralmente alunos veteranos, voluntários da instituição ou da própria comunidade.

f) Premiações: opcionalmente, pode-se trabalhar com premiações no modelo gamificado de medalhas. Se for o caso, sugere-se confeccionar cinco (ou seis) medalhas: uma de ouro para o campeão do Summaê, uma de prata para o vice-campeão, uma de bronze para o melhor chapéu (celebridade do evento) e duas (ou três) de bronze para os autores do melhor vídeo.

g) Instruções prévias aos estudantes: cada participante deve estar com um chapéu e levar uma caneta azul e outra vermelha, caso se deseje trabalhar com soluções em papel na hora do evento. Também é possível trabalhar com soluções por meio de algum aparelho digital, facilitando o envio das respostas. Essa é uma boa medida para EaD e educação corporativa.

h) Organização do ambiente: o espaço onde será realizado o evento deve conter projetor e som para o computador, podendo ser também preparada, opcionalmente, decoração de acordo com a escolha de uma temática.

i) Seleção de vídeos: alguns vídeos devem ser selecionados para utilização no evento, considerando o tempo para sua realização. A quantidade deve variar de acordo com o evento, mas uma média de seis vídeos por hora pode ser um bom ponto de partida. A escolha dos vídeos deve ser feita com base na criatividade e originalidade, mas deve levar em conta a questão formulada e o acréscimo que oferece ao debate com relação aos demais vídeos escolhidos.

j) Lista com os vídeos selecionados: uma boa medida é fazer uma lista dos vídeos e respectivas perguntas, organizando-os por assunto e fazendo marcações para os vídeos principais (por exemplo, utilizando asterisco). Assim, é mais fácil organizar o tempo do evento, escolhendo eventualmente os vídeos entre os já selecionados. $\mathrm{Na}$ lista, também é possível inserir os respectivos 
endereços da web, para que os estudantes possam acessá-los posteriormente.

k) Desafio final: é necessário elaborar um desafio final que seja um problema mais amplo que as questões dos vídeos, preferencialmente sendo uma aplicação dos conceitos, de modo a ser trabalhado em pequenos grupos.

1) Programação do evento: redigir a programação do evento é uma boa forma para ter controle das atividades que serão realizadas, principalmente se envolver desafios intermediários, apresentações artísticas, intervalos ou coffee break.

No dia do evento, alguns colaboradores devem ficar responsáveis pela entrada no ambiente e por um acolhimento agradável. Som ambiente pode criar um clima emocionalmente propício, mas deve-se considerar a exigência do chapéu e das canetas azuis e vermelhas. Esse é um bom momento para distribuir folhas em branco para as respostas das questões que serão trabalhadas durante o evento e reservar algumas canetas avulsas a ser emprestadas para os estudantes que necessitarem desse apoio pode agilizar o processo de entrada.

Ao iniciar o evento, sugere-se anunciar os professores da mesa como primeiro momento do Summaê ou realizar alguma apresentação artística. Cada professor da mesa deve receber uma lista com os vídeos e uma caneta, de modo que possam avaliar os vídeos e saber previamente as questões para se organizar nas respostas ou debate.

O Summaê é uma atividade bastante gamificada e sua base segue um ciclo simples:

a) apresentação de vídeo,

b) tempo para soluções,

c) apresentação de solução ou versão do especialista,

d) critérios para correção,

e) abertura para pequenos debates e autocorreção por parte dos estudantes (Figura 1). 
Figura 1 - Fluxograma básico do Summaê

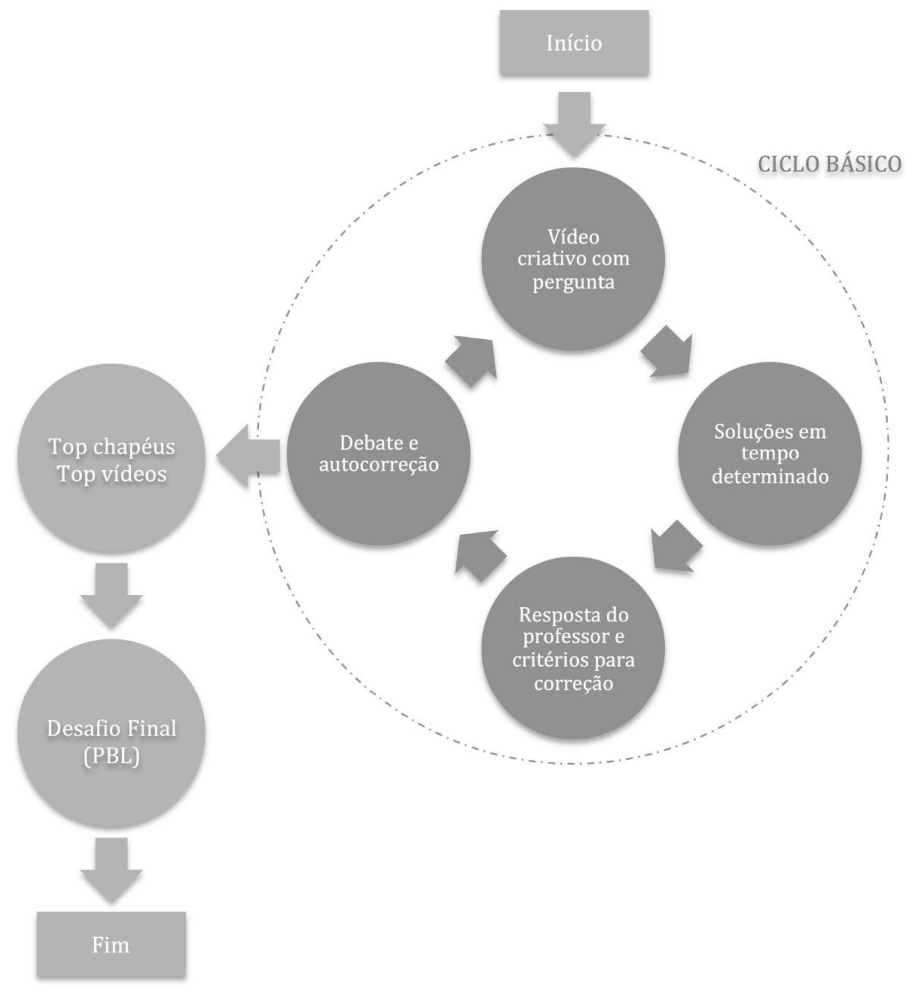

Fonte: Os autores (2017).

O ciclo tem início com a apresentação do primeiro vídeo selecionado, seguida de um tempo estipulado para que os estudantes resolvam a questão na folha recebida. Nesse momento, deve-se utilizar a caneta azul. Enquanto eles resolvem a questão, é possível colocar uma música ambiente; já os professores atribuem uma nota de zero a dez para o vídeo na lista recebida. Após o término do tempo, os estudantes devem trocar a caneta azul pela vermelha, ficando as entidades responsáveis por fiscalizar o procedimento. 
Enquanto os estudantes resolvem a questão, os professores devem conversar entre si para chegar a um acordo sobre quem irá apresentar uma solução possível para a questão e liderar um possível debate. O professor da mesa que se sentir à vontade anuncia sua resposta e, no fim, estipula critérios para que os estudantes façam a autocorreção das soluções feitas. Durante esse processo, é muito comum surgirem divergências ou novos caminhos de solução, sendo um excelente momento para debater o tema. Quando todos os estudantes tiverem corrigido suas questões, trocam de caneta novamente, é executado o próximo vídeo da lista e o ciclo reinicia.

Vale acrescentar que os critérios de correção devem ser similares de um vídeo para outro, havendo certa homogeneidade entre as questões. Normalmente, são atribuídos de três a cinco pontos para cada questão, divididos em alguns pontos-chave.

Em geral, os critérios são do tipo: "quem falou sobre isso ganha um ponto e quem falou também sobre aquilo ganha mais um ponto" ou "quem isolou a variável ganha um ponto". Outra opção é trabalhar com questões de múltipla escolha, porém se corre o risco de reduzir as divergências e, consequentemente, o debate. Vídeos cujas questões apresentam múltiplas escolhas podem ser uma excelente estratégia para utilizar o Summaê na EaD, pois as correções são feitas automaticamente e sem maiores dificuldades.

Enquanto os vídeos são projetados e o jogo de perguntas e respostas acontece, a equipe de fotos registra o evento e fica responsável também por escolher os top chapéus. Em eventos pequenos, com até 30 participantes, podem ser escolhidos os cinco melhores e, em eventos com mais de 30 participantes, os dez melhores. A equipe seleciona os chapéus por meio das fotos e passa as imagens para o responsável pelos vídeos, que irá projetá-las em momento oportuno. $\mathrm{Na} \mathrm{EaD}$, as fotos dos participantes podem ser enviadas por eles mesmos para algum gerenciador de arquivos.

Após o término dos vídeos, o professor solicita que os participantes somem todos os pontos feitos e escrevam o resultado na parte de cima da folha, ao lado da identificação do estudante. As entidades recolhem todas as folhas de resposta e saem do ambiente para a verificação dos finalistas. 
No período entre a execução do último vídeo e o recolhimento das folhas de resposta, os professores devem chegar a um acordo sobre quais são os três melhores vídeos. Após a saída das entidades, tem-se o melhor momento para anunciar os top chapéus no projetor e realizar a escolha da celebridade do evento por meio de palmas. A celebridade será quem receber mais palmas entre os top chapéus.

Após a eleição da celebridade do evento, é feita a escolha do melhor vídeo, também por meio de palmas. No caso de se trabalhar com medalhas, a celebridade do evento e os autores do melhor vídeo recebem uma medalha de bronze.

O tempo utilizado para a escolha dos top chapéus e melhor vídeo é intencional e serve para que as entidades verifiquem as autocorreções dos estudantes, o que pode ser feito de modo bastante simples. Como o objetivo é selecionar os dois alunos que fizeram mais pontos, basta verificar se eles corrigiram suas questões corretamente, não sendo necessária a verificação de todas as resoluções feitas. Outra ação possível é selecionar os cinco ou seis estudantes que fizeram mais pontos e comparar suas soluções.

Os dois estudantes mais bem pontuados são anunciados e cada finalista deve formar um grupo com mais três ou quatro colegas para o desafio final, que também é disponibilizado a todos os estudantes da plateia e deve ser resolvido em um prazo delimitado.

Os professores analisam as soluções e o campeão do Summaê será o estudante finalista que tiver apresentado a melhor solução com o apoio da equipe formada; consequentemente, o vice-campeão será o outro finalista. Medalhas de ouro e prata são entregues, no caso de se trabalhar com medalhas, ao primeiro e segundo colocados, respectivamente.

Opcionalmente, é possível avaliar também a melhor resolução para o desafio final, entre os demais participantes, oferecendo outra medalha de bronze, se for o caso. O uso de tecnologia, como o uso de site, aplicativo ou formulário on-line, pode auxiliar na agilidade desse processo.

Definir uma temática artística ao organizar um Summaê pode facilitar na organização de atividades extras, como desafios adicionais, apresentações artísticas, encenações teatrais ou simplesmente fantasiar 
professores e entidades. Enfim, as possibilidades são muitas e cada organizador deve investigar o nível de não convencionalidade que deseja atribuir ao seu Summaê, estando certo de que apenas o jogo de perguntas e respostas baseado nos vídeos, o conjunto de professores e um ambiente em que todos estejam usando chapéus já serão suficientes para a criação de um espaço lúdico, profícuo e criativo.

Nesse contexto, o objetivo principal deste artigo é avaliar, sob a óptica do professor, quais foram as possíveis dificuldades encontradas, vantagens, reações observadas e o engajamento dos estudantes, em diferentes áreas do conhecimento, na experiência com o Summaê.

\section{Metodologia}

Este artigo é um estudo retrospectivo, exploratório-descritivo, de abordagem qualitativa. Os participantes foram escolhidos por conveniência, obedecendo ao critério de inclusão de serem professores ou não, tendo utilizado o Summaê em suas disciplinas ou contextos de trabalho. Assim, foram selecionados 18 participantes.

Para coleta de dados, foi aplicado um questionário, disponibilizado em ambiente on-line e elaborado pelos autores do artigo, com perguntas abertas que permitissem avaliar a percepção do professor ao utilizar o Summaê em sua disciplina. $\mathrm{Na}$ análise dos resultados, os sujeitos participantes foram denominados com o termo Professor 1, 2, 3 e assim por diante como medida de preservação de suas identidades.

Os dados foram analisados por meio de análise de conteúdo.

\section{Resultados e discussão}

Os 18 sujeitos que participaram deste estudo são de diferentes unidades da federação: Distrito Federal, Goiás, Minas Gerais, Paraná, Santa Catarina e São Paulo, sendo dos municípios de Rio do 
Sul e Presidente Getúlio, em Santa Catarina; Maringá, no Paraná; Belo Horizonte e Contagem, em Minas Gerais; Anápolis, em Goiás; Sorocaba, em São Paulo; e Brasília, no Distrito Federal.

As instituições as quais os participantes pertencem são: Unicesumar, com quatro professores; UnB, Centro Universitário Una e Centro Universitário para o Desenvolvimento do Alto Vale do Itajaí (UNIDAVI), com três professores cada; Faculdade de Engenharia de Sorocaba (FACENS), com dois participantes; Centro Universitário do Distrito Federal (UDF), Centro Universitário Projeção e Centro Universitário de Anápolis (UniEvangélica), com um professor cada. Os participantes da Unicesumar realizaram o Summaê na EaD.

Dos 18 participantes, 5 declararam que não tinham experiência com metodologias não convencionais, enquanto os demais citaram exemplos aplicados por eles, como um quiz jurídico (jogo simulando um município para ensinar questões tributárias e fiscais) e uso de maquetes para ensinar amostragem em uma disciplina de Estatística.

As disciplinas em que foi utilizado o Summaê foram de diversas áreas: Psicometria, Gestão Integrada da Qualidade, Equipes Multidisciplinares, Projetos, Cálculo I e II, Estatística, Processo Civil, Direito Administrativo, Direito Civil, Direito Penal, Do Átomo à Vida 3, Planejamento Estratégico, Imagenologia, Metodologia do Trabalho Científico, Avaliação da Aprendizagem e Ensino, Políticas e Estrutura da Educação Física, Evolução do Pensamento Administrativo e Introdução à Administração. Um dos participantes aplicou o Summaê a 800 colaboradores administrativos de uma instituição de ensino.

O número de edições realizadas pelos respondentes variou bastante. Teve participante que aplicou a metodologia apenas uma vez, tendo a organizado pela primeira vez há alguns meses, enquanto outro já havia organizado sete edições do evento.

Quando foram perguntados sobre a reação dos estudantes no momento em que foi proposta a realização do Summaê, os termos "curiosidade", "surpresa" e "estranhamento" foram os mais mencionados pelos participantes. Alguns apontaram que sentiram certa resistência. 
Uma mistura de curiosidade sobre a forma que funcionaria o evento e o significado do nome e animação por ser aplicada uma atividade diferente (Professor 1).

Quanto à avaliação do engajamento dos alunos durante a atividade, muitos dos participantes avaliaram positivamente esse aspecto. Alguns arriscaram até um percentual de engajamento, dizendo que foi de $100 \%$.

Super participativos no chat da aula ao vivo. Conseguimos uma interação muito grande em cada vídeo/pergunta lançada (Professor 2).

Ficaram totalmente engajados, a ponto de que, na hora de responder as perguntas dos vídeos, havia um silêncio total na sala (Professor 1).

Jang, Reeve e Deci (2010) verificaram, em sua pesquisa, que o engajamento dos alunos pode ser maior se o professor não se limita a estruturar lições e metas ou oferecer feedback, mas apoia a autonomia dos estudantes. De fato, o Summaê é uma atividade que invoca o empoderamento do estudante, pela possibilidade de criar seus vídeos e elaborar suas próprias questões, conforme verificado no depoimento seguinte:

O Summaê permite captar melhor a atenção dos alunos e permite fixar conteúdos de maneira mais eficiente, visto que os alunos lembram dos vídeos ao serem questionados sobre os conteúdos trabalhados. Além disso, como os vídeos são produzidos pelos próprios alunos, a aula fica mais atraente para eles, pois ficam interessados pelo que foi produzido pelos colegas (Professor 3).

Por se tratar de um ambiente lúdico e por todo o planejamento previamente realizado para a atividade, a confiança construída na relação professor-aluno e a própria animação do professor durante a execução da atividade interferem nos níveis de engajamento (BRACKETT et al., 2012), conforme observado a seguir:

O engajamento foi total. Já realizamos o evento com os colaboradores há vários anos, mas pela primeira vez, vimos o público totalmente engajado em participar da dinâmica. Fizemos também o concurso de chapéus. Foi um sucesso (Professor 4). 
O fato de o estudante estar imerso e totalmente envolvido por um ambiente de aprendizagem que evoca experiências emocionais precipita um envolvimento mais profundo com o aprendizado (HAMARI et al., 2016). Outro ponto que coaduna com a atividade do Summaê é apontado pelo estudo de Hamari et al. (2016), em que há evidências de que a fantasia por meio de simulações e jogos promove uma motivação intrínseca e pode melhorar a aprendizagem, em comparação com a instrução sem esses elementos.

Sobre as reações emocionais dos alunos durante a atividade, de maneira geral, os professores avaliaram como positivas. Termos como alegria, entusiasmo e empolgação foram muito mencionados pelos participantes. Nenhum referiu que tenha observado emoções negativas durante a atividade. Um professor mencionou, inclusive, o reconhecimento de seu esforço pelos seus alunos:

Os alunos ficaram extasiados com a atividade. Reações de alegria, contentamento e entusiasmo foram as mais percebidas. Recebi muitos elogios e ouvi a frase 'você é uma professora que se preocupa com seus alunos e que ama o que faz' inúmeras vezes. É como se os alunos reconhecessem o professor que busca estratégias diferentes como alguém especial (Professor 3).

Hamari et al. (2016), em seu artigo sobre a "gamificação", relatam experimentos recentes em neurociência que demonstraram que, ao verificar o cérebro de uma pessoa que lê um romance e está totalmente envolvida, há a ativação não apenas das áreas de atenção, mas também das responsáveis pelas emoções. No Summaê, existe a construção de um ambiente totalmente diferente e temático, favorecendo a construção de um ambiente de imersão e emocionalmente propício à aprendizagem.

Ao solicitar ao participante que comparasse o Summaê com as aulas de exercícios convencionais, foi mencionada a presença da participação ativa, bem como a questão de ser uma atividade dinâmica que desperta o trabalho em equipe, a presença do lúdico, o incentivo à criatividade, a interatividade e a vantagem de facilitar a fixação dos conteúdos, o que demonstra, de certa forma, um aprendizado social. 
Espaço para a criatividade, para vermos os alunos interagindo entre si, coisa que muitas vezes não acontece em aulas tradicionais e também a oportunidade dos alunos nos verem de uma forma diferente, positiva e desconstruindo o paradigma de que professor sabe tudo e só está ali para 'empilhar' mais e mais conteúdos (Professor 5).

Impossivel comparar, com certeza um erro ou um acerto no Summaê ficarão gravados para sempre. Enquanto em uma aula convencional poucos retêm o conhecimento, alguns não participam por medo de errar e os que acertam aprendem a ser individualistas. No Summaê o resultado é da equipe, trabalho em time (Professor 6).

De acordo com os depoimentos dos participantes, verifica-se que o Summaê proporcionou, de certo modo, uma forma de aprendizado social e emocional, algo que vai além do conteúdo proposto na disciplina. Pesquisadores afirmam que, quando ocorrem tais aprendizados (social e emocional) em sala de aula, há o desenvolvimento de competências importantes, como a capacidade de gestão das emoções, a preocupação com o outro e a capacidade de estabelecer relações positivas e de decisões mais responsáveis (BRACKETT et al., 2012). Além disso, os aprendizados social e emocional facilitam o desempenho acadêmico e reduzem problemas de comportamento, estresse, ansiedade e depressão (BRACKETT et al., 2012).

Quando perguntados se tiveram alguma dificuldade ao realizar o Summaê, os participantes afirmaram que, de modo geral, não tiveram dificuldades significativas. Algumas áreas apontaram problemas restritos ao domínio da tecnologia, pela necessidade de produção de vídeos, o que não prejudicou a realização da atividade.

[A maior dificuldade foi] Conter a alegria dos alunos e segurar a reclamação de outras turmas vizinhas reclamando do barulho, sem entender o que estava acontecendo. Outro ponto é a produção de vídeos pelos alunos que nunca vivenciaram a dinâmica. É bastante trabalhoso para o professor que organiza, mas o resultado é gratificante. Faríamos tudo novamente 1000 vezes só pelo prazer de ver nossos alunos engajados e empoderados (Professor 6). 


\section{Considerações finais}

Este artigo apresentou uma possibilidade de transformar qualquer espaço em um ambiente lúdico e criativo para trabalhar conceitos com base em questões formuladas pelos estudantes, fazendo-os sujeitos ativos no processo de ensino-aprendizagem. Dessa forma, sabe-se que a aprendizagem ativa traz benefícios no que tange ao aspecto da liberdade de exploração dos estudantes perante seus próprios objetivos e interesses e também quanto ao engajamento em sala de aula ou em ambientes informais.

Em síntese, observou-se que a atividade do Summaê foi realizada em diversos campos do conhecimento, em 19 disciplinas, de instituições distintas de cinco estados brasileiros e do Distrito Federal, incluindo o ensino superior presencial, EaD e Educação Corporativa. Os resultados mostraram que a metodologia ativa proposta foi capaz de transformar o ambiente educacional, de maneira a favorecer a interação professor-aluno e aluno-aluno.

Assim, o Summaê é uma metodologia capaz de criar um clima emocional em sala de aula, propício ao engajamento e com melhores resultados, quando comparado aos métodos convencionais, de acordo com os participantes.

\section{Referências}

BRACKETT, M. A. et al. Assessing teachers' beliefs about social and emotional learning. Journal of Psychoeducational Assessment, v. 30, n. 3, p. 219-236, 2012.

CROPLEY, D. H. Promoting creativity and innovation in Engineering education, Psychology of aesthetics. Creativity and the Arts, v. 9, n. 2, p. 161-171, 2015. 
FRAGELLI, R. R. et al. Summaê: um método diferente para o ensino de integrais. In: INTERNATIONAL SYMPOSIUM ON PROJECT APPROACHES IN ENGINEERING EDUCATION. 1., 2012, São Paulo. Proceedings..., São Paulo: PUCSP, 2012. p. 109-114.

FRAGELLI, R. R.; FRAGELLI, T. B. O. Trezentos: a dimensão humana do método. Educar em Revista, n. 63, p. 253-265, 2017.

GRAY, P. Free to learn: why unleashing the instinct to play will make our children happier, more self-reliant, and better students for life. New York: Basic Books, 2013.

HAMARI, J. et al. Challenging games help students learn: an empirical study on engagement, flow and immersion in game-based learning. Computers in Human Behavior, n. 54, p. 170-179, 2016.

HOFFMAN et al. The perceived effects of faculty presence vs. absence on small-group learning and group dynamics: a quasi-experimental study. BMC Medical Education, v. 14, n. 1, p. 258-265, 2014.

HOFSTEIN, A.; ROSENFELD, S. Bridging the gap between formal and informal science learning. Studies in Science Education, v. 28, n. 1, p. 87-112, 1996.

JANG, H.; REEVE, J.; DECI, E. L. Engaging students in learning activities: it is not autonomy support or structure but autonomy support and structure. Journal of Educational Psychology, v. 102, n. 3, p. 588-600, 2010.

LAI, C. et al. Using positive visual stimuli to lighten the online learning experience through in class questioning. International Review of Research in Open and Distributed Learning, v. 17, n. 1, p. 23-41, jan. 2016.

PARTNERSHIP FOR 21ST CENTURY SKILLS (P21). Framework for 21st century learning. 2014. Disponível em: <http://www.p21.org/our-work/p21-framework >. Acesso em: 11 maio 2017.

PATRICK, H.; KAPLAN, A.; RYAN, A. M. Positive classroom motivational environments: convergence between mastery goal structure and classroom social climate. Journal of Educational Psychology, v. 103, n. 2, p. 367-382, 2011. 
REYES, M. R. et al. Classroom emotional climate, student engagement, and academic achievement. Journal of Educational Psychology, v. 104, n. 3, p. 700-712, 2012.

ROCKMAN, S.; BASS, K.; BORSE, J. Media-based learning science in informal environments. Learning science in informal environments committee of the National Research Council National Academy of Science, 2007. Disponível em: <https://rockman.com/docs/downloads/MediaBasedLearningScience.pdf $\rangle$. Acesso em: 10 maio 2017.

ROGERS, C. R. Liberdade para aprender. Belo Horizonte: Interlivros, 1973.

ROGERS, C. R . Tornar-se pessoa. São Paulo: Martins Fontes, 1991.

SEFTON-GREEN, J. Learning at not-school: a review of study, theory, and advocacy for education in non-formal settings. Massachusetts: MIT Press, 2013.

STEWART, O. G.; JORDAN, M. E. "Some explanation here": a case study of learning opportunities and tensions in an informal science learning environment. Instructional Science, v. 45, n. 2, p. 137-156, 2016.

SUMMAÊ. Breve história do Summaê. Disponível em: <http://summaeh.com/historia>. Acesso em: 12 maio 2017.

TUYAY, S.; JENNINGS, L.; DIXON, C. Classroom discourse and opportunities to learn: an ethnographic study of knowledge construction in a bilingual third-grade classroom. Discourse Processes, v. 19, n. 1, p. 75-110, 1995.

Recebido: 19/04/2017

Received: 04/19/2017

Aprovado: 25/05/2017

Approved: 05/25/2017 